\title{
RELATO DE EXPERIÊNCIA COM ADOLESCENTES DE UMA ESCOLA DO MUNICÍPIO DE SANTA CRUZ DO SUL
}

\author{
RODRÍGUEZ, P. J. L1; PLATES, C2; MAZONI, A; FANCK, L2; BOFF, A³
}

PALAVRAS-CHAVE: Adolescência. Oficinas. Saúde Mental. Pandemia.

\begin{abstract}
RESUMO
O seguinte trabalho trata-se de um relato de experiência de oficinas desenvolvidas pela Liga Acadêmica de Psiquiatria da Universidade de Santa Cruz do Sul (LAP-UNISC), com adolescentes do Ensino Fundamental e Ensino Médio de uma escola privada do município de Santa Cruz do Sul. Com a pandemia Covid-19 e a suspensão das aulas presenciais, as dinâmicas foram adaptadas para o ambiente virtual, com o intuito de continuar proporcionando espaços de diálogos e reflexão acerca de diversos temas, como valorização da vida e bullying. De modo geral, as oficinas foram bem recebidas e avaliadas pelos alunos, com a maioria alegando que proporcionaram reflexões acerca do dia a dia na escola e que participariam novamente de outras oficinas da Liga Acadêmica de Psiquiatria. Percebeu-se que as atividades contribuíram para estimular a reflexão sobre as temáticas propostas e discussões entre os alunos. No que se refere à adaptação para a modalidade virtual, prejuízos e/ou obstáculos para a realização das oficinas não foram observados, possivelmente, devido à familiarização dos alunos com a plataforma utilizada, visto que as aulas estavam acontecendo no mesmo espaço virtual.
\end{abstract}

\section{REPORT OF AN EXPERIENCE WITH ADOLESCENTS FROM A SCHOOL IN THE CITY OF SANTA CRUZ DO SUL}

KEYWORDS: Adolescence. Workshops. Mental Health. Pandemic.

\begin{abstract}
The following paper is an experience report of workshops developed by the Academic League of Psychiatry at the University of Santa Cruz do Sul (LAP-UNISC), with adolescents in elementary and high school from a private school in the city of Santa Cruz do Sul. With the Covid-19 pandemic and the suspension of face-to-face classes, the dynamics were adapted to the virtual environment, in order to continue providing spaces for dialogue and reflection on various topics relevant to the public. In general, the workshops were well received and evaluated by the students, with most claiming that they provided reflection and that they would participate again in other workshops of the Academic League of Psychiatry. It was perceived that the activities contributed to stimulate reflection on the proposed themes and discussions among the students. With regard to the adaptation to the virtual modality, losses and/or obstacles to the workshops were not observed, possibly due to the students' familiarity with the platform used, since the classes were taking place in the same virtual space.
\end{abstract}

\footnotetext{
1 Acadêmico do curso de Medicina na Universidade de Santa Cruz do Sul.

2 Acadêmico do Curso de Psicologia na Universidade de Santa Cruz do Sul.

${ }^{3}$ Doutor em Medicina, e docente do Departamento de Ciências da Saúde Universidade Federal de Santa Cruz do Sul abcdboff@gmail.com
} 


\section{INTRODUÇÃO}

A pandemia exigiu, no mundo todo, confinamento, fechamento de escolas e distanciamento físico. A consequência disso é a restrição dos movimentos, a interrupção da rotina e a diminuição das interações sociais. No âmbito escolar, esse afastamento dos métodos tradicionais de ensino vem aproximando os alunos de quadros de estresse e ansiedade (UNESCO, 2020). Frente a essa realidade, fica evidente a necessidade de um olhar atento aos estudantes com o intuito de promover momentos de acolhimento, escuta e reflexão. Tais momentos já representavam uma atividade desenvolvida pela Liga Acadêmica de Psiquiatria da Universidade de Santa Cruz do Sul antes do surgimento da pandemia da COVID-19, entretanto, a migração do ensino presencial para o remoto, aliada à demanda de cuidado à saúde mental dos estudantes fez com que as tradicionais oficinas promovidas precisassem de reformulação para o novo cenário. Frente a isso, foram realizadas oficinas semanais na modalidade online, através da plataforma Google Meet, com a participação de adolescentes do Ensino Fundamental de uma escola privada do município de Santa Cruz do Sul, que possui vínculo com a instituição de ensino superior, dessa forma, as oficinas foram realizadas em parceria das redes APESC (Associação Pró-Ensino Em Santa Cruz Do Sul).

As oficinas, anteriormente realizadas de forma presencial, fazem parte das atividades anuais da Liga Acadêmica e são divididas em Módulo I, contemplando as turmas do oitavo ano; e Módulo II, contemplando turmas do nono ano do Ensino Fundamental. No que se refere às Ligas Acadêmicas, entende-se que é importante que proporcionem não apenas atividades de pesquisa, mas sobretudo a aproximação e inserção dos acadêmicos na comunidade, contribuindo através de atividades educativas, preventivas e de promoção à saúde (AZEVEDO, DINI, 2006). Nessa perspectiva, segundo Lopes (2011) o desenvolvimento de oficinas aproxima os acadêmicos da comunidade ao mesmo tempo em que se propõe a criar espaços voltados à promoção de saúde, acolhimento e reflexão. Através desse método, é possível criar vínculos e oportunidades de reflexões de projetos de vida, além de estimular o espaço dos sujeitos se conhecerem dentro do grupo.

Como referido anteriormente, a dinâmica tradicionalmente pensada para essas atividades foi adaptada para o ambiente virtual, inclusive com a inserção de temáticas consideradas pertinentes para o momento, como o distanciamento social. Em outras palavras, as oficinas foram repensadas não apenas em formato, mas principalmente em conteúdo, de modo que o período de atividade contemplasse assuntos atuais e de interesse do público. Nesse sentido, objetiva-se relatar o trabalho de educação em saúde, cuja realização se deu através de oficinas temáticas, a saber: valorização da vida e distanciamento social, impactos do machismo e masculinidade tóxica, bullying, sexualidade e população LGBTQIA+ (lésbicas, gays, bissexuais, transexuais, travestis, queer, intersexo e assexuais). A escolha das referidas temáticas foi realizada a partir de uma discussão prévia com a responsável pela escola parceira da ação, a qual sinalizou temáticas de interesse dos alunos, as quais foram adaptadas pelos coordenadores responsáveis pela oficina, buscando a articulação com o contexto pandêmico, a exemplo da oficina sobre distanciamento social, entre as demais que também trouxeram conexões com o cenário de saúde. Entende-se que a ampla disseminação de informação, o que buscou ser realizado em cada encontro. é importante para a construção da cidadania, como aponta Alvarenga (1999) apud Luna; Kutianski (2018), assim como o incentivo a processos comunicativos de discussões críticas referentes ao desenvolvimento de uma sociedade mais justa e caracterizada por mais oportunidades ao indivíduos. 


\section{FUNDAMENTAÇÃO TEÓRICA}

\subsection{Pandemia e a modalidade de aulas remotas}

Os primeiros casos de infecção pelo Sars-Cov-2 foram identificados em dezembro de 2019, após causar uma série de casos de pneumonia de causa desconhecida, até então, em Wuhan, na China (WANG et al, 2020). Desde então, a nova doença se espalhou por mais de 206 países e foi declarada como sendo uma pandemia pela Organização Mundial da Saúde (OMS) (SCHMIDT et al., 2020). Para enfrentar a propagação do vírus, foram implementadas várias medidas de contenção, como o distanciamento e o isolamento social, além do fechamento de escolas e universidades (PEREIRA et al, 2020).

\subsection{Valorização da vida e distanciamento social}

Em todo o mundo, o suicídio está entre as cinco principais causas de morte na faixa etária dos 15 a 19 anos, sendo que em muitos países está classificado como primeira ou segunda causa de morte (ORGANIZAÇÃO MUNDIAL DA SAÚDE, 2000). No que se refere ao Brasil, dados apontam que também existe uma tendência de crescimento nos casos de suicídio entre adolescentes (CICOGNA; HILLESHEIM; HALLAL, 2019). Frente a isso, dois motivos colocaram a temática sobre valorização da vida como importante: o primeiro é o contexto de pandemia, cujos impactos na saúde mental, segundo Greff (2020), podem envolver "desde reações normais e esperadas de estresse agudo por conta das adaptações à nova rotina, até agravos mais profundos no sofrimento psíquico". Diante desse cenário, estratégias de prevenção, acompanhamento e posvenção com o intuito de promover bemestar à população se fazem necessárias, visto que as estatísticas demonstram um crescimento nos casos de tentativas e suicídios após eventos extremos (GREFF, 2020).

O segundo motivo é a realidade local, dado que o Rio Grande do Sul "é o Estado brasileiro que historicamente tem apresentado os maiores coeficientes de suicídio do País ", sobretudo com a população idosa (MENEGHEL et al). Embora esses coeficientes façam referência a outra faixa etária, é importante considerar a influência desse contexto, principalmente associado ao momento de pandemia, cujo cenário pode desencadear ou agravar problemas de saúde mental, especialmente depressão e ansiedade, consequentemente elevando o risco de comportamento suicida (GREFF, 2020). Os adolescentes, assim como as crianças, não constituem um grupo de risco para a COVID-19, entretanto, quando se pensa na perspectiva da saúde mental esse cenário muda porque tal público é um dos mais afetados diretamente pelas medidas de isolamento, além do enfrentamento de diversos outros desafios como o próprio ensino à distância, afastamento dos amigos, pais estressados, entre outros (ROHDE, 2020). Além do isolamento e dos impactos deste, é preciso evidenciar o aumento no número de contaminados pelo vírus e o excesso de informações, por vezes contraditórias, que acabam impulsionando o adoecimento psicológico, reverberando em consequências na saúde mental (LIMA et al., 2020). 


\subsection{Impactos do machismo e masculinidade tóxica}

A masculinidade é estabelecida a partir da incessante comprovação social, não só de se encaixar nos padrões do masculino mas também de ter completa aversão ao feminino. A ideia de 'não ser como as mulheres' e também a depreciação ao que é considerado feminino perpassa toda a construção do que é ser homem atualmente. (BAÉRE; ZANELLO; 2020).

Segundo Zanello (2018), os homens brasileiros tendem a sofrer com os atravessamentos de uma virilidade sexual e laborativa, que de forma compulsória os subjetiva. 0 homem é sempre representado socialmente como forte, potente e dominante em suas relações, com isso, a mulher é vista como o objeto e como o exemplo do que o homem não pode ser em seu meio, pois é considerada o oposto da virilidade e da força masculina. Além disso, no ramo laboral, o poder aquisitivo é visto como uma característica importante para a construção dessa masculinidade.

As consequências da masculinidade tóxica e do machismo estruturado socialmente não atingem apenas as mulheres. Os homens e meninos são diariamente atravessados por conceitos equivocados do que é ser homem, que causam transtornos por conta da pressão estabelecida de como agir. Temos como efeitos da reprodução dessas problemáticas, índices altos de violência contra a mulher, LGBTQIAfobia e maior nível de suicídio do sexo masculino (BRAZ, 2004).

De acordo com o Ministério da Saúde (2017), entre 2011 e 2016, 79\% dos casos de suicídio foram do sexo masculino no Brasil. Além disso, conforme a OMS (2014), os dados registram maior risco de suicídio para homossexuais e bissexuais, por conta de sintomas depressivos, ansiosos e a violência reproduzida pelo preconceito. Ademais, a violência contra a mulher também é fruto de uma sociedade que ensina o homem a ser violento e se sentir superior às mulheres e a todos que são considerados 'afeminados'.

Para Arendt (2003), o ser humano é um sujeito comum que faz o que é esperado em relação às demandas sociais, que são (re)produzidas pelas classes dominantes, na intenção de manter o modelo estabelecido. Com isso, pode-se pensar que o homem quando causa a violência, ele está reproduzindo o que foi ensinado e pressionado a ser. É de extrema importância que os meninos sejam ensinados o cuidado, a gentileza e principalmente a entender e expressar seus sentimentos, para que seja trabalhada a sensibilidade e a empatia necessária. (BRAZ, 2004).

\subsection{Bullying}

Bullying é uma palavra de origem estrangeira e ainda sem tradução na língua portuguesa, que é usada para fazer referência a um conjunto de atitudes de violência física e/ou psicológica (VECHI, 2012). Para Neto (2005), o bullying compreende todos os comportamentos agressivos, intencionais e repetitivos, sem motivação evidente, adotadas por um ou mais estudante contra outro(s), causando dor e angústia, sendo executadas dentro de uma relação com desequilíbrio de poder. Além disso, o bullying apresenta uma série de características que o diferencia de outras formas de violência, sendo a mais preocupante delas, a propriedade de causar traumas psíquicos à vítima e aos envolvidos (FANTE, 2005). Segundo dados de Pimentel et al (2020), não só houve uma 
correlação positiva entre ser vítima de bullying e ter sintomas depressivos, ansiedade e estresse, e ser vítima e ter ideação suicida, como $48,71 \%$ da amostra da pesquisa apresentava ideação suicida.

Existem 3 papéis no fenômeno do bullying, podendo ser interpretados por uma ou mais pessoas: a vítima, o agressor e a testemunha. Geralmente, as vítimas apresentam algum tipo de diferença em relação ao grupo, que acabam por ser a causa das perseguições, humilhações, intimidações e exclusões. Alguns sinais frequentemente encontrados em vítimas de bullying são: não querer ir à escola, pedir para trocar de escola constantemente, apresentar baixa no rendimento escolar, abandono escolar e isolamento. 0 agressor é aquele que, usando de uma posição de "poder", ataca os mais fracos. Geralmente possui alguma característica que o destaque e justifique seu "poder", como por exemplo, serem maiores ou mais fortes fisicamente e/ou se destacarem em atividades esportivas (CHIORLIN, 2007). Podem, mas não necessariamente, manter ao redor de si um grupo de seguidores que o auxiliam nas agressões. As testemunhas, por sua vez, são aqueles alunos que presenciam o acontecimento do bullying, porém se omitem da situação, não indo ao auxílio da vítima, tampouco se juntam aos agressores (VECHI, 2012). Geralmente são simpatizantes da vítima, porém não se intrometem com medo de que venham a sofrer represálias ou a ser as próximas vítimas.

É um fenômeno de complexidade muito alta, e que pode ocorrer em diversos contextos. No entanto, ele se torna mais preocupante quando ocorre dentro do ambiente escolar, pois este é tido como um local seguro, onde os adolescentes são capazes de desenvolver suas habilidades intelectuais e sociais (LOPES NETO, 2015). Algumas pesquisas nos levam a acreditar que a permanência do adolescente nesse ambiente por várias horas possa ser um fator que favorece o surgimento recorrente de conflitos e intimidações sistemáticas com seus colegas (ALENCASTRO et al, 2020; CAVALCANTI et al, 2019). Tendo em vista que a Constituição da República Federativa do Brasil, o Estatuto da Criança e do Adolescente e a Convenção sobre os Direitos da Criança da Organização das Nações Unidas, preveem o direito à dignidade e entendem a educação como um meio de prover o pleno desenvolvimento da pessoa e seu preparo para o exercício da cidadania (LOPES NETO, 2005), se torna imprescindível conscientizar crianças, adolescentes e professores de que o bullying é inaceitável e não será tolerado, permitindo o combate a esse problema de forma mais clara.

\subsection{Sexualidade e população LGBTQIA+}

A sexualidade pode ser compreendida como um processo construído ao longo do desenvolvimento dos sujeitos, se manifestando com mais intensidade na adolescência, fase marcada por grandes mudanças físicas e comportamentais influenciadas por fatores socioculturais e familiares. 0 processo de crescimento marcado por essa fase é repleto de descobertas, curiosidade por novas experiências e desenvolvimento da personalidade e manifestação da identidade sexual, entendendo a adolescência como um corpo em desenvolvimento (SOARES et al, 2008).

As questões de sexualidade fazem parte do processo de transformação da adolescência e com elas estão atreladas diversas curiosidades marcadas pelo abandono da auto-imagem infantil e projeção de vida no mundo adulto. No entanto o exercício da sexualidade de forma irresponsável pode acarretar conflitos e alterações nos planos futuros como uma possível gravidez, abortos, doenças sexualmente transmissíveis, evasão escolar etc. (SOARES et al, 2008). 
O surgimento da educação sexual nas escolas se deu no século XX tendo como principal demanda o controle epidemiológico. Na época os discursos eram repressivos e sustentados pela religião. Com o avanço das discussões políticas e dos direitos sexuais e reprodutivos ampliam-se as discussões frente a temática, possibilitando um olhar para a mesma como prática aliada à saúde física e mental. Ainda segundo o autor o processo de educação sexual ainda acontece informalmente nas relações familiares e formalmente, como prática pedagógica em escolas e instituições sociais (FURLANETTO et al, 2018)

A educação escolar representa um caminho para a instauração de uma Educação Sexual no processo de adolescer, na qual visa o respeito à livre orientação sexual e manifestações de gênero. (MEIRELES, 2019). Para SILVA (2011), a escola apresenta a função de promover a educação para a cidadania, tendo como dever o respeito a todos, sem distinção de classe, raça e gênero. Deste modo percebendo a escola como um espaço de promover e facilitar as relações de cooperação entre instituição educativa, família e comunidade. Furlanetto et al (2018), refere que a sexualidade perpassa as fases do desenvolvimento humano e a educação sexual escolar deve ter caráter sistemático, contínuo e abrangente.

\section{MATERIAIS E MÉTODOS}

Partindo do objetivo de promover o cuidado e informação em saúde, especialmente diante do contexto de pandemia, a plataforma online Google Meet foi utilizada como principal recurso por permitir o contato e aproximação com os alunos. Os encontros, com duração de cerca de uma hora, aconteceram entre as aulas e foram combinados previamente com os responsáveis pela escola. Slides elaborados com base em cada temática serviram de material de apoio, assim como vídeos e reportagens. Foram totalizados quatro encontros, caracterizados pela metodologia participativa e dialogal. 0 número de encontros foi definido a partir da organização do cronograma da escola, visto que as oficinas aconteceram entre as aulas, sendo necessária uma adaptação para que fosse possível a dedicação de pelo menos 60 minutos para a atividade. Participaram 40 adolescentes entre 13 e 14 anos, estudantes das duas turmas de $8^{\circ}$ ano do ensino fundamental da escola. As referidas turmas participam anualmente de projetos envolvendo a ministração de oficinas, sendo uma atividade prevista para os alunos matriculados naquele ano. A realização da atividade transcorreu sem a identificação de nenhum obstáculo, visto que os alunos já estavam adaptados ao formato online, bem como com os espaços de discussão e reflexão. Entretanto, foi importante a adaptação das atividades em uma das turmas devido a presença de um aluno com deficiência visual, exigindo dos coordenadores da oficina a leitura e descrição dos slides e vídeos utilizados como recursos. A avaliação das oficinas foi realizada através de formulário online desenvolvido na plataforma Google Forms, o qual foi enviado às turmas ao final do último encontro visando compreender a satisfação dos adolescentes em relação ao conjunto de atividades, bem como entender quais foram as avaliadas como favoritas para nortear futuras oficinas. Foi deixado um campo livre para sugestões, críticas e comentários, porém nenhum aluno preencheu. 


\subsection{Oficina 1: Valorização da vida e Distanciamento Social}

Por ser o primeiro contato com os alunos, inicialmente foi preparado um momento de apresentação da Liga e dos acadêmicos com o intuito de apresentar a proposta da atividade. Em seguida foi realizada uma breve contextualização da temática, abordando a adolescência enquanto uma etapa marcada por transformações e posteriormente estimulando a reflexão sobre valorização da vida através de um quiz online com mitos e verdades sobre o suicídio. A plataforma utilizada foi o Kahoot, "considerado uma ferramenta de avaliação gamificada porque ele incorpora alguns elementos de games como: feedback imediato, níveis, pontuação, entre outros “ (SILVA; SALES; CASTRO, 2019).

As frases utilizadas no quiz foram: "quando o adolescente pensa em se suicidar terá risco de suicídio para o resto da vida”, "os adolescentes que ameaçam se matar não farão isso, pois querem chamar apenas atenção", "não devemos falar sobre suicídio com adolescentes, pois isso pode aumentar o risco", "o suicídio está aumentando entre os adolescentes", "existem sites e aplicativos que incentivam o suicídio", "a causa do suicídio é sempre única", "ideias de morte são coisas de adolescente" e "depressão é o transtorno mental mais comum entre as pessoas que cometem suicídio". Cada aluno acessava o Kahoot com um código fornecido pelos acadêmicos integrantes da Liga Acadêmica de Psiquiatria e, enquanto as frases eram apresentadas no Google Meet, os alunos respondiam (anonimamente) se aquela afirmação era mito ou verdade. Após cada rodada acontecia um momento de comentários. Ademais, a dinâmica da oficina também envolveu o compartilhamento de reportagens sobre a relação entre isolamento social e depressão, servindo como disparadoras de reflexão sobre o momento vivenciado por todos. Por fim, foram abordadas dicas para lidar com a ansiedade e cuidar da saúde mental na pandemia.

\subsection{Oficina 2: Impactos do Machismo e Masculinidade tóxica}

No segundo contato com os alunos, foi novamente elaborada uma apresentação de slides para que fosse feita uma contextualização a respeito do assunto. Nessa apresentação, foi definido o conceito de masculinidade tóxica e apresentados alguns dos impactos do mesmo, representados por índices de violência contra a mulher e impactos da masculinidade tóxica na saúde mental dos meninos. Também foram trazidas formas de construir uma masculinidade saudável e, em casos de necessidade, contatos de telefone do Serviço de Proteção de Crianças e Adolescentes, do Centro de Atendimento da Mulher e do Centro de Valorização da Vida.

Nesta oficina, foi optado por substituir a avaliação gamificada do primeiro encontro por um tempo mais extenso de discussão. Antes do início da discussão, foi passado um vídeo educativo para melhor ilustrar o que foi previamente exposto e para facilitar o início da conversa.

\subsection{Oficina 3: Bullying}

No que tange a estrutura do encontro, a terceira oficina muito se assemelhou com a segunda. A apresentação de slides preparada para essa atividade abordou o conceito e os tipos de bullying, os participantes desse fenômeno (o agressor e a vítima), os sinais que a vítima de bullying pode apresentar e as consequências 
de tal ato. Deve-se enfatizar que, devido à pandemia de COVID-19 e as aulas em modalidade remota, foi destacada a modalidade virtual do bullying, o cyberbullying.

Ao final dessa apresentação, também foi passado um vídeo para contextualizar e facilitar o início da discussão. 0 vídeo em questão foi o trailer do filme "Extraordinário", que conta a história de um garoto com uma deformidade facial que pela primeira vez na sua vida, vai para uma escola regular e sofre bullying por sua condição.

\subsection{Oficina 4: Sexualidade + População LGBTQIA+}

Na última oficina realizada com as turmas do oitavo ano, a liga convidou uma psicóloga formada na UNISC para dividir o espaço de fala. No material preparado pela psicóloga, foram abordadas as diferenças entre sexo, sexo biológico, identidade de gênero, expressão de gênero e orientação sexual e alguns aspectos relacionados as formas e ao combate ao preconceito sofrido pela população LGBTQIA+. Devido à participação da convidada, não foi realizada atividade gamificada nem passado vídeo, seguindo diretamente para discussão com a turma.

\section{RESULTADOS E DISCUSSÃO}

A adolescência é marcada por um processo de desenvolvimento biopsicossocial, podendo ser um período atravessado por crises, dificuldades, angústia e mal-estar. Tais características fazem desse público uma faixa etária que requer um olhar caracterizado pela sensibilidade, configurando um cuidado amplo (ARAÚJO et al, 2015). Nessa perspectiva, entende-se que a escola representa um espaço que viabiliza esse cuidado amplo, podendo atuar como promotora de saúde e qualidade de vida, sobretudo através do acesso à informação, conforme foi realizado nas oficinas ministradas. Sendo a escola um dos ambientes em que o adolescente está inserido e sendo estes ambientes dotados de possibilidades para influenciar as condições do existir do sujeito, ações que transformam os indivíduos podem ser pensadas nesse espaço, preparando esse público para lidar com as adversidades e auxiliando na construção de uma educação alicerçada na saúde e incentivadora da articulação entre saberes (BUSS; 2001; CARVALHO, 2015).

0 questionário de satisfação enviado aos alunos possibilitou a compreensão do efeito da ação desenvolvida. Dos alunos que participaram, 61,1\% se mostraram satisfeitos e 38,9\% muito satisfeitos. Quando questionados sobre a qualidade das oficinas, $61,1 \%$ qualificaram o conteúdo das oficinas como sendo excelente, $16,7 \%$ como sendo muito bom, 11,1\% bom e 5,6\% regular. Quando questionados se os encontros proporcionaram alguma reflexão por parte do aluno, 83,3\% declararam que sim, 11,1\% mais ou menos e 5,6\% alegaram que não. Com base nesses resultados, entende-se que as oficinas promoveram a articulação de saberes citada por Carvalho (2015), visto que se tornaram um espaço de encontro e de trocas tanto de saberes quanto afetivas, impactando no desenvolvimento integral dos alunos. Dentre as quatro oficinas, a intitulada "Sexualidade e LGBTQIA+" foi a favorita de $38,9 \%$ dos que responderam o questionário, seguida pela "Valorização da Vida" e "Bullying”, ambas com 22,2\%. Quando questionados se estariam dispostos a participar de outra oficina da Liga de Psiquiatria, 55,6\% responderam que sim, 22,2\% talvez e 22,2\% não. 
Avalia-se a participação na atividade como importante por possibilitar a vivência de uma troca em que cada um encontrava espaço para expressar suas angústias, dúvidas e demais sentimentos, movimento esse que de acordo com Campos (2015) permite que por meio da fala o indivíduo expresse seu modo de perceber a si, o outro e o mundo ao mesmo tempo em que consegue refletir sobre suas angústias e trazê-las para a consciência. Tal apontamento é corroborado pelo dado já indicado acerca das reflexões proporcionadas pelas oficinas, com 83,3\% declarando algum tipo de reflexão. Resultados semelhantes foram encontrados em atividade realizada com cerca de 91 estudantes de uma escola pública no interior de São Paulo através de oficinas abarcando aspectos psicológicos e psicopedagógicos. A avaliação geral das referidas oficinas revela que tais momentos criaram espaços de fala, escuta e troca coletiva, bem como reflexões sobre os modos singulares de pensar e agir (KOEHLER et al, 2021)

Para melhor contextualização, é importante ressaltar que o projeto das oficinas era originalmente realizado de forma presencial, sem a presença da figura de um professor na sala de aula, apenas os ligantes e os alunos. Com a necessidade de transformá-la em modalidade remota, as atividades com os alunos, que eram mais dinâmicas, tiveram de ser adaptadas para discussões com os mesmos, e acabou por se fazer necessário a presença de um professor na sala, para que o link da aula continuasse o mesmo.

Com base nesses dados, percebe-se que mesmo na modalidade remota as oficinas alcançaram o objetivo: estimular a reflexão acerca de temas atuais e promover um espaço de troca. Ao longo dos encontros a participação dos alunos indicava interesse pelas temáticas e valorização do espaço criado entre as aulas para discussões não relacionadas às tarefas escolares. Desse modo, percebe-se a importância de promover momentos de escuta e trocas, sobretudo nesse momento de pandemia em que o contato entre os alunos está restrito. As oficinas se configuram, nesse cenário, como uma oportunidade não apenas para trabalhar temáticas importantes na adolescência, mas também para direcionar um olhar para a saúde mental dos alunos, promovendo interação entre eles e cuidado em saúde.

\section{CONCLUSÃO}

Percebeu-se que as atividades contribuíram para estimular a reflexão sobre as temáticas propostas e trocas de experiência entre os alunos. No que se refere à adaptação para a modalidade virtual, prejuízos e/ou obstáculos para a realização das oficinas não foram observados, possivelmente, devido à familiarização dos alunos com a plataforma utilizada, visto que as aulas estavam acontecendo no mesmo espaço virtual. Os alunos se mostraram satisfeitos com as discussões, ademais a Liga da Psiquiatria pôde observar quais assuntos mais interessaram o público-alvo. Os resultados obtidos através da experiência de oficinas temáticas com adolescentes podem contribuir para estimular a inserção comunitária e principalmente a atuação direta de estudantes da área da saúde na psicoeducação dos jovens em período escolar. Através de um vínculo entre a comunidade escolar e os acadêmicos, segundo Lopes et al (2011), é possível aprofundar as discussões a respeito de necessidades individuais e coletivas, além de promover um momento de convivência entre o grupo e ampliar o contexto escolar para além de questões de aprendizagem curricular, mas também olhar para o subjetivo e individual. 


\section{REFERÊNCIAS}

ARAÚJO, L. et al. Viver saúde: promoção de qualidade de vida de adolescentes vulneráveis em um projeto social. Sanare, v.14, n.1, 2015. Disponível em: https://sanare.emnuvens.com.br/sanare/article/view/615. Acesso em: 23 nov 2021.

ARENDT, H. Eichmann em Jerusalém: uma reportagem sobre a banalidade do mal. SILVA, A.C. (Trad.) Coimbra: Tenacitas, [1963] 2003.

AZEVEDO, R.P.; DINI, P.S. Guia para construção de Ligas Acadêmicas. Ribeirão Preto: Assessoria Científica da Direção Executiva Nacional dos Estudantes de Medicina, 2006. Disponível em: http://www.daab.org.br/texto.asp?registro=157

ALENCASTRO, L. C. S. et al. Theater of the Oppressed and bullying: nursing performance in school adolescent health. Rev. Brasileira de Enfermagem, Brasília. Disponível em: http://dx.doi.org/10.1590/0034-7167-20170910 . Acesso em: 16 abr. 2020.

BAERE, F.; ZANELLO, V. SUICÍDIO E MASCULINIDADES: UMA ANÁLISE POR MEIO DO GÊNERO E DAS SEXUALIDADES. Psicol. Estud., Maringá, v. 25, e44147, 2020. Disponível em: http://www.scielo.br/scielo.php?script=sci_arttext\&pid=S1413-73722020000100208\&lng=en\&nrm=iso . Acesso em 26 mar. 2021.

BRASIL. Ministério da Saúde. Boletim Epidemiológico 08. Abr/2020. Disponível em: https://www.saude.gov.br/images/pdf/2020/April/09/be-covid-08-final-2.pdf . Acesso em: 26 mar 2021.

BRAZ, M. A Construção da Subjetividade Masculina e Seu Impacto sobre a Saúde do Homem: reflexão bioética sobre justiça distributiva. Ciência e Saúde, 2004. Disponível em: https://www.scielo.br/pdf/csc/v10n1/a10v10n1.pdf . Acesso em: 26 mar. 2021

BUSS, P. M. Promoção da saúde na infância e adolescência. Rev. Bras. Saúde Mater. Infant., Recife, v. 1, n. 3, p.279-282, dez. 2001. Disponível em: <http://www.scielo.br/scielo.php?script=sci_arttext\&pid=S151938292001000300010\&lng=en\&nrm=iso> Acesso em: 23 nov 2021

CAMPOS, V. F. Linguagem e psicoterapia gestaltista: como se aprende a falar. São Paulo: Ideias \& Letras, 2015.

CARVAlHo, A. I. Princípios e prática da promoção da saúde no Brasil. Cad. Saúde Pública, Rio de Janeiro, v. 24, n. 01, p. 4-5, jan. 2008. Disponível em: <https://www.scielo.br/pdf/csp/v24n1/00.pdf> Acesso em: 23 nov 2021

CAVALCANTI, J. G. et al. Bullying no Contexto da Adolescência: Um Estudo das Representações Sociais. Revista de Psicologia da IMED, Passo Fundo, v. 11, n.2, p.96-114, jul/dez 2019. Disponível em: https://doi.org/10.18256/2175- 5027.2019.v11i2.3287 . Acesso em: 24 abr. 2020.

CHIORLIN, M. de O. A influência do bullying no processo ensino-aprendizagem. Monografia, Universidade Federal de São Carlos, São Carlos, 2007.

CICOGNA, J.I.; HILLESHEIM, D.; HALLAL, A.L. Mortalidade por suicídio de adolescentes no Brasil: tendência temporal de crescimento entre 2000 e 2015. J. bras. psiquiatr., Rio de Janeiro, v.68, n.1, p. 1-7, 2019. Disponível em: <https://www.scielo.br/scielo.php?script=sci_arttext\&pid=S0047-20852019000100001> . Acesso em: 26 mar 2021

MEIRÉLES, C.; R. de C. A. R. K. da S. Educação e Diversidade: trabalhando questões de gênero e sexualidade com adolescentes em escolas públicas. Mediação, [S. I.], n. 9, p. 26-31, 2019. Disponível em: https://revista.uemg.br/index.php/mediacao/article/view/4332 . Acesso em: 30 mar. 2021. 
NETO, A A. L. Bullying: saber identificar e como prevenir. 1 ed. São Paulo: Brasiliense, 2011.

FANTE, C. Fenômeno bullying: como prevenir a violência nas escolas e educar para a paz. 2 ed. Campinas: Versus, 2005.

FURLANETTO, M.F. et al. Educação sexual em escolas brasileiras: revisão sistemática da literatura. Cad. Pesqui. São Paulo, v. 48, n. 168, p. 550-571, Jun 2018. Disponível em:

http://www.scielo.br/scielo.php?script=sci_arttext\&pid=S0100-15742018000200550\&Ing=en\&nrm=iso . Acesso em: 30 mar. 2021.

GREFF, A. P. et al. Saúde mental e atenção psicossocial na pandemia COVID-19: suicídio na pandemia COVID19. Rio de Janeiro: Fiocruz, 2020. 24 p. Cartilha. Disponivel em:

https://www.arca.fiocruz.br/handle/icict/41420 . Acesso em: 25 mar 2021.

KOEHLER, S. et al. A escola como promotora da saúde mental e do bem-estar juvenil: oficinas pedagógicas com adolescentes. Desidades. n.29, 2021. Disponível em: <http://desidades.ufrj.br/featured_topic/a-escola-comopromotora-da-saude-mental-e-do-bem-estar-juvenil-oficinas-pedagogicas-com-adolescentes/3/> Acesso em: 23 nov 2021

LIMA, C. et al. The emotional impact of Coronavirus 2019-nCoV (new Coronavirus disease). Psychiatry Research, vol. 287, n1, 2020. Disponível em: https://pesquisa.bvsalud.org/portal/resource/pt/mdl-32199182 Acesso em: 25 mar 2021.

LOPES, A.N. Bullying: comportamento agressivo entre estudantes. J. Pediatr. (Rio J.), Porto Alegre, v. 81, n. 5, supl. p. s164-s172, Nov. 2005. Disponível em: http://www.scielo.br/scielo.php?script=sci_arttext\&pid=S002175572005000700006\&lng=en\&nrm=iso . Acesso em: 22 Mar. 2021.

LOPES, R. E. et al. (2011) Oficinas de atividades com jovens da escola pública: tecnologias sociais entre educação e terapia ocupacional. Interface - Comunicação, Saúde, Educação [online]. 2011, v. 15 , n. 3. Disponível em: <https://doi.org/10.1590/S1414-32832011000100021>. Acesso em: 23 nov 2021.

LUNA, T.; KUTIANSKI, A. 0 consumo de informações sobre saúde por adolescentes do $8^{\circ}$ ano do ensino fundamental. E-mosaicos. v.7, n.15, 2018. Disponível em: https://www.e-publicacoes.uerj.br/index.php/emosaicos/article/view/34185. Acesso em: 23 nov 2021

MENEGHEL, S. et al (2004). Características Epidemiológicas do Suicídio no Rio Grande do Sul. Revista de Saúde Pública, 38 (6): 804-810. Disponível em: <https://www.scielo.br/pdf/rsp/v38n6/08.pdf>. Acesso em: 24 mar 2021.

ORGANIZAÇÃO MUNDIAL DA SAÚDE. Prevenção do suicídio: manual para professores e educadores. Departamento de Saúde Mental. Genebra, 2000. Disponível em: https://www.who.int/mental_health/prevention/suicide/en/suicideprev_educ_port.pdf Acesso em: 26 mar 2021.

ORGANIZACIÓN MUNDIAL DE LA SALUD (2014). Prevención del suicídio: un imperativo global. Washington, D.C.: Organización Panamericana de la Salud.

PEREIRA, M.D et al (2020). The COVID-19 pandemic, social isolation, consequences on mental health and coping strategies: an integrative review. Research, Society and Development. Disponível em: https://rsdjournal.org/index.php/rsd/article/view/4548 Acesso em: 24 mar 2021

PIMENTEL, F. de O.; DELLA MEA, C. P.; DAPIEVE PATIAS, N. Victims of bullying, symptoms of depression, anxiety and stress, and suicidal ideation in teenagers, Bogotá, v. 23, n. 2, p. 230-240, Dez. 2020. Disponível em: http://www.scielo.org.co/scielo.php?script=sci_arttext\&pid=S0123-91552020000200230\&lng=en\&nrm=iso . Acesso em: 22 mar. 2021. 
ROHDE, L. Guia de Saúde Mental Pós-Pandemia no Brasil. Instituto de Ciências Integradas, 2020. Disponível em: http://biblioteca.cofen.gov.br/wp-content/uploads/2020/12/Guia-de-saude-mental-pos-pandemia-no-Brasil.pdf Acesso em: 25 mar 2021

SCHMIDT, B. et al. Saúde mental e intervenções psicológicas diante da pandemia do novo coronavírus (COVID19). Estudos de Psicologia (Campinas) [online]. 2020, v. 37 Disponível em: https://doi.org/10.1590/19820275202037 e200063. Acesso em: 23 mar 2021.

SILVA, J. B. da; SALES, G. L.; CASTRO, J. B. de. Gamificação como estratégia de aprendizagem ativa no ensino de Física. Rev. Bras. Ensino Fís., São Paulo, v. 41, n. 4, e20180309, 2019. Disponível em: https://www.scielo.br/scielo.php?pid=S1806-11172019000400502\&script=sci_arttext Acesso em: 25 mar 2021.

SILVA, K. Currículo, gênero e sexualidade na formação de professores. Dissertação de Mestrado apresentado na Universidade federal de Juiz de fora. Departamento de Educação.UFJF, mar. 2011.

SOARES, S.M. et al. Oficinas sobre sexualidade na adolescência: revelando vozes, desvelando olhares de estudantes do ensino médio. Esc. Anna Nery, Rio de Janeiro, v. 12, n. 3, p. 485-491, Set. 2008. Disponível em: http://www.scielo.br/scielo.php?script=sci_arttext\&pid=S1414-81452008000300014\&Ing=en\&nrm=iso . Acesso em: 30 mar. 2021.

UNESCO. Covid-19, Resposta Educacional. Nota informativa - Setor de Educação. Disponível em: https://unesdoc.unesco.org/ark:/48223/pf0000373271_por Acesso em: 25 mar 2021.

VECHI, A. D. K. Bullying: o perigo nas escolas. Revista de Educação, v. 15, n. 19, 2012.

WANG C. et al. Immediate Psychological Responses and Associated Factors during the Initial Stage of the 2019 Coronavirus Disease (COVID-19) Epidemic among the General Population in China. Int J Environ Res Public Health. 2020. Disponível em: https://pubmed.ncbi.nlm.nih.gov/32155789/ Acesso em: 25 mar 2021;

ZANELLO, V. Saúde mental, gênero e dispositivos: cultura e processos de subjetivação. Curitiba: Appris, 2018. 